\title{
Kinetics studies of the polymerization and analysis of the mechanical behavior of the adhesive hysol EA-9321
}

\author{
O. Devaux ${ }^{1,2}$, J.Y. Cognard ${ }^{1}$, R. Creac'hcadec ${ }^{1}$, N. Carrere $^{1}$ and F. Lavelle ${ }^{2}$ \\ ${ }^{1}$ LBMS, ENSTA Bretagne, Brest, France \\ ${ }^{2}$ CNES, Paris, France
}

Structural adhesive bonding is well-etablished in the spatial industry, especially on the Ariane 5 SYLDA. This one enables the launcher to carry a second satellite inside the fairing. In most cases, joints can be fabricated indoors under controlled conditions. However, SYLDA structure is exposed to thermal and mechanical loads due to its lifecycle (from the transport to the launching).

The cold-curing adhesive used on SYLDA is the Hysol EA-9321. Until now, few studies have been carried on the influence of the curing degree on the mechanical behaviour of bonding joints. It is one of the objectives of this work.

The curing kinetics of the adhesive will be investigated in order to study their impact on the mechanical behavior of the Hysol EA-9321 during SYLDA's lifecycle.

\section{KINETICS ANALYSIS}

A heat-flux differential scanning calorimeter (DSC) was used to investigate kinetic studies of the adhesive on sample weight ranging between 5 to $10 \mathrm{mg}$.

Dynamic scans were conducted in the temperature range of $25^{\circ} \mathrm{C}$ to $250^{\circ} \mathrm{C}$ at constant heating rates of 5 , 10,15 and $20^{\circ} \mathrm{C} / \mathrm{min}$ in order to determine the total heat of reaction [1]. This value is determined by integrating heat flux vs. time under the exotherm, as shown in Fig. 1. This heat of reaction is independent of the heating rate $\left(\Delta \mathrm{H}_{T}=341.44 \pm 2.5 \mathrm{~J} / \mathrm{g}\right)$.

Isothermal scans were conducted at temperatures ranging between 25 and $100{ }^{\circ} \mathrm{C}$. The aim is to determine the heat released during isothermal scanning and to predict the evolution of the curing degree [2]. For each isothermal temperature, the curing degree increases until a plateau (Fig. 2). At high temperatures, the plateau is reached after few minutes : $90 \%$ of curing requires 41 minutes. At low temperatures curing, this one is delayed: $40 \%$ is attained after 11 hours at $25^{\circ} \mathrm{C}$.

Higher temperatures accelerate the reaction between resin and hardener. Hence, the plateau is quickly reached for high-curing temperatures.

\section{BEHAVIOR OF THE ADHESIVE HYSOL EA-9321 FOR PROPORTIONAL LOADINGS}

The behavior of the adhesive EA-9321 for tension/ compression-shear loadings was experimental determined

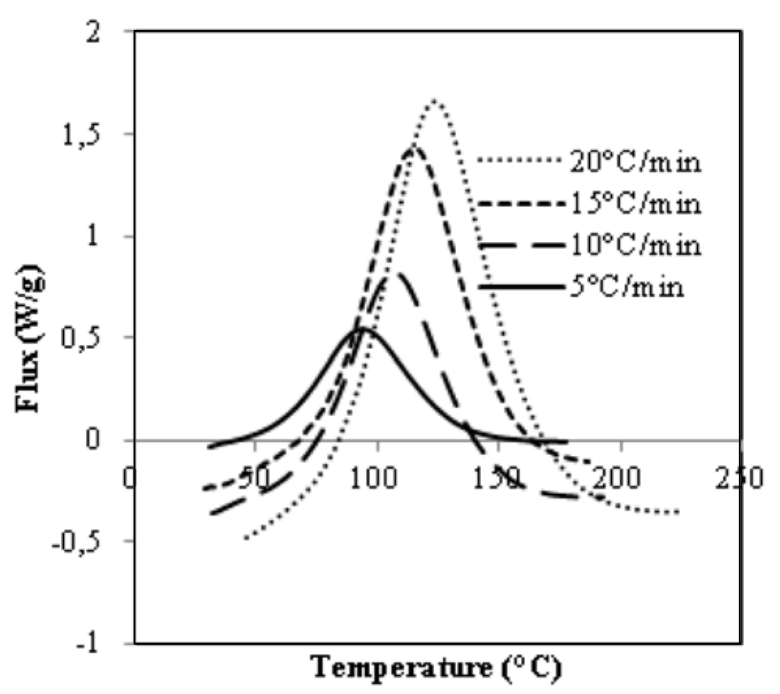

Figure 1. Flux vs. Temperature at different heating rates.

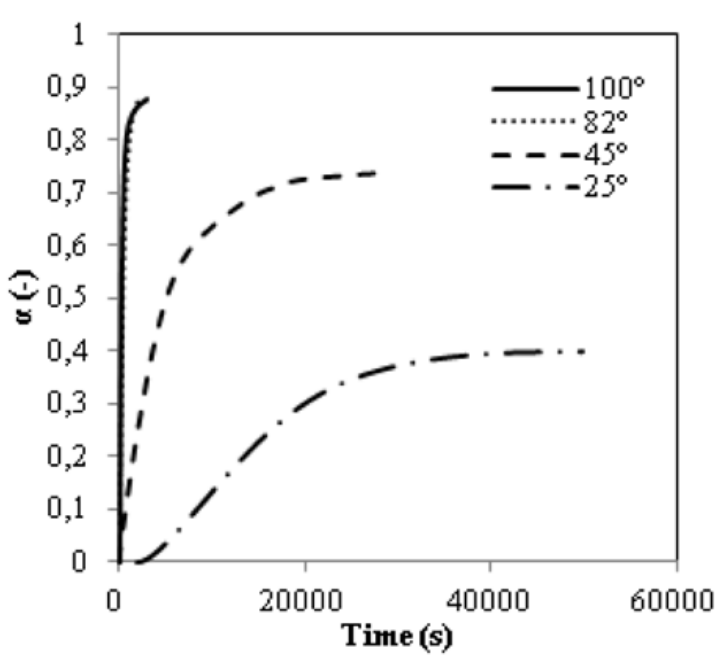

Figure 2. Curing degree $\alpha$ vs. Time at different isothermal temperatures.

thanks to the modified Arcan device [3] for several curing degree at different curing cycle. The Arcan device is able to predict the behavior of an adhesive in an assembly under proportional loads. The fracture envelope is shown in Fig. 3. For tension/compression-shear loads for a curing cycle of 1 hour at $82^{\circ} \mathrm{C}$ (curing degree of 0.9 ). The scatter 


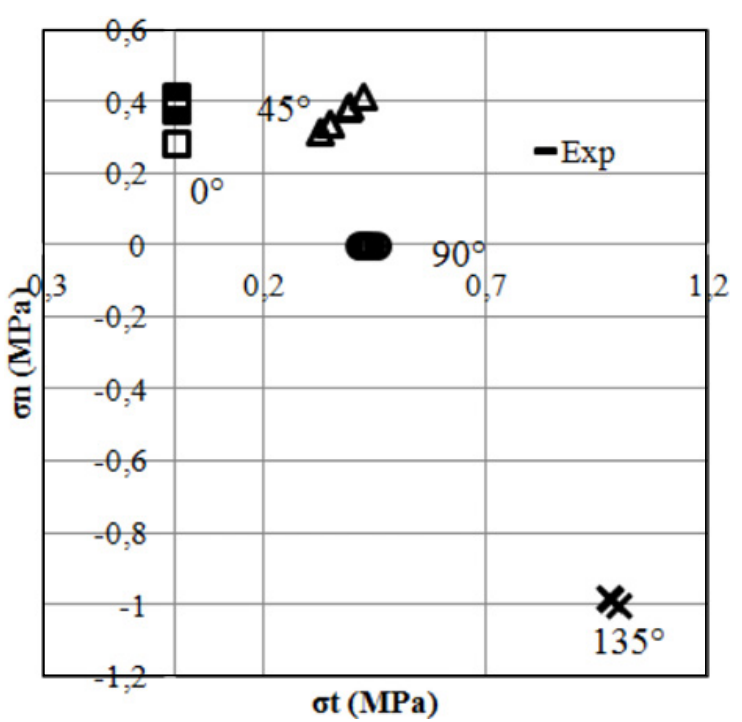

Figure 3. Tension/compression-shear fracture envelope of Hysol EA-9321 for a curing of 1 hour at $82{ }^{\circ} \mathrm{C}$.

of the experimental results is lower for shear $\left(90^{\circ}\right)$ and compression-shear $\left(135^{\circ}\right)$ loads.

The adhesive EA-9321 is tougher for normal than for tangential loadings.

\section{CONCLUSION}

The curing degree is now known for several curing cycle thanks to the DSC analysis. Starting from this study, the mechanical properties for proportional loadings have been investigated for several curing degree at different curing cycle. The aim of this work is to characterize the behavior of bonding joints by taking into account the impact of the curing degree on its mechanical behavior.

\section{References}

[1] L. Sun, S. Pang A. Sterling, M. Stubblefield, Dynamic analysis of curing process of Epoxy Prepreg, J. App. Polym. Sci 2002.

[2] Kissinger, Reaction kinetics in differential thermal analysis, Anal. Chem 1957.

[3] J. Maurice, J.Y. Cognard, R. Créac'hcadec, P. Davies, L. Sohier, S. Mahdi, Characterization and modelling of the 3D elastic-plastic behaviour of an adhesively bonded joint under monotonic tension/compression-shear loads : influence of three cure cycles, J. of Adhes. Sci. and Technol., 2012. 